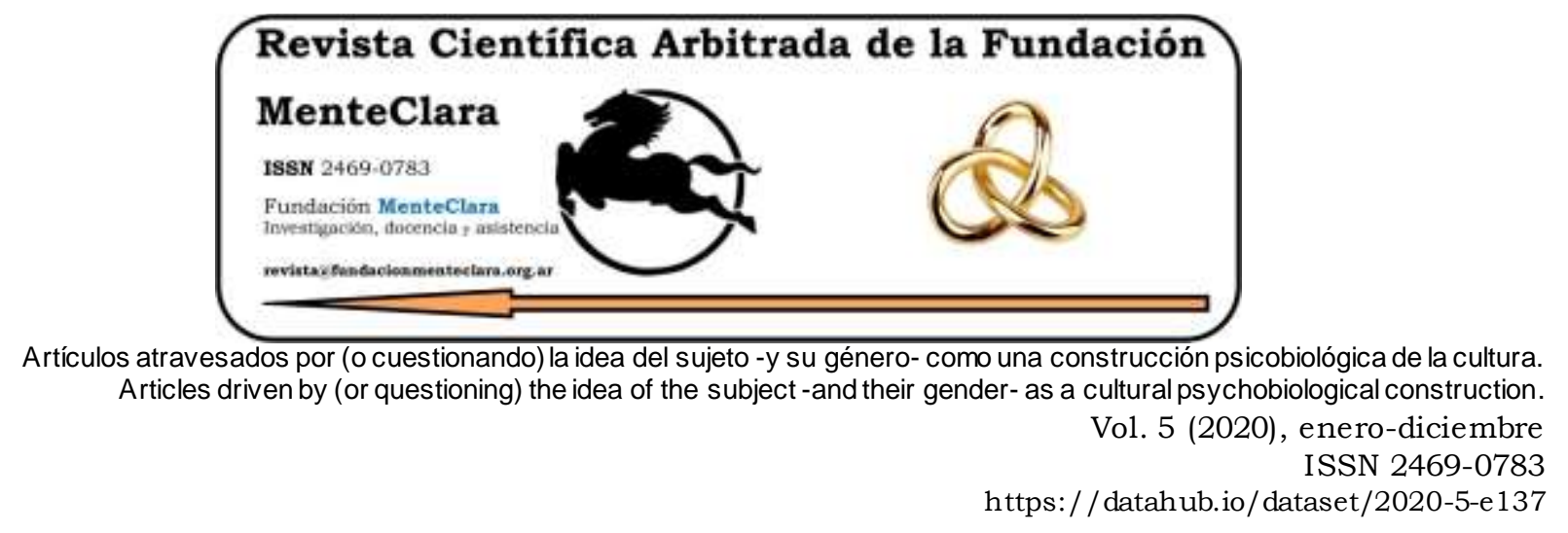

\title{
LA CONSTITUCIÓN ARGENTINA Y LOS TIEMPOS DEL F.M.I. - DE ARAMBURU A MACRI
}

THE ARGENTINE CONSTITUTION AND THE TIMES OF THE IMF - FROM ARAMBURU TO MACRI

Jorge Francisco Cholvis jorgecholvis@yahoo.com.ar Universidad Nacional de Lanús, Argentina

Cómo citar este artículo / Citation: Cholvis, J. F. (2020). "La Constitución argentina y los tiempos del F.M.I. - De Aramburu a Macriv. Revista Cientifica Arbitrada de la Fundación MenteClara, Vol. 5 (137).

DOI: https://doi.org/10.32351/rca.v5.137

Copyright: ( 2020 RCAFMC. Este artículo de acceso abierto es distribuido bajo los términos de la licencia Creative Commons Attribution 4.0 International License (CC BY 4.0). Recibido: 01/02/2020. Aceptado: 04/02/2020 Publicación online: 05/02/2020

Conflicto de intereses: Ninguno que declarar.

\section{Resumen}

Este artículo expone los resultados producidos por la restauración del modelo económico basado en la toma de crédito del Fondo Monetario Internacional y sus políticas recomendadas. Recorre la historia política y jurídica de la Argentina desde 1956, cuando dan comienzo políticas económicas que postulan al capital extranjero como motor del desarrollo, otorgan prioridad al mercado y marginan al Estado del proceso económico para llegar al actual estado socioeconómico pasando por los diseños técnico-jurídico utilizados para su concepción y ejecución en los diferentes períodos caracterizados por el ingreso de la Argentina al FMI. Finalmente expone, a la luz de los indicadores actuales de la economía, las ventajas y desventajas del modelo neoliberal para los diferentes sectores de la sociedad. 


\begin{abstract}
This article shows the results produced by going back to the economic model based on loans from the International Monetary Fund and its recommended policies. It covers Argentina's political and legal background as from 1956, when economic policies highlighting foreign capital as a development gateway, prioriziting the market and relegating the State from the economic process began, to the current socioeconomic state including the technical and legal tools used for the model's conception and execution in the different periods Argentina joined the IMF. Finally, it argues, in the light of the current economic indicators, the advantages and disadvantages of the neoliberal model for the different sectors of society.
\end{abstract}

Palabras Claves: Constitución; Deuda externa; F.M.I.; supraconstitucionalidad defacto; sometimiento neocolonial; soberanía

Keyw ords: Constitution; External debt; IMF; de facto supra-constitutionality; neocolonial subjugation; sovereignty 


\section{Las duras consecuencias de la restauración neoliberal}

Con la asunción del gobierno de Macri, se retomó el antiguo modelo económico basado en el endeudamiento externo y la valorización financiera que rápidamente revirtió negativamente las mejoras alcanzadas por el país en los indicadores de deuda pública existentes a diciembre de 2015, dado que se habian logrado reducir los niveles de endeudamiento a valores históricos: de un $160 \%$ del PBI a un $46 \%$ aprox.

En 2016 la Argentina es el país que más se endeudó. De tal modo, condicionará la agenda económica del futuro gobierno. La deuda contraída por Macri totaliza u\$s 187.706 millones y el gobierno siguiente tendrá vencimientos de deuda en moneda extranjera por casi u\$s 150.000 millones entre 2020/2023. Las emisiones del Tesoro nacional lideran el ranking de endeudamiento. Aun se aguarda al respecto una definida y firme presencia del Congreso Nacional.

Dólares que se pasan a pesos en una revivida bicicleta financiera para obtener enormes ganancias aprovechando las altas tasas de interés que después se fugan a guaridas financieras off-shore, tal los denominados "paraísos fiscales", que amparan a sociedades para el saqueo y conforman instrumentos de lo que se conoce como la versión "salvaje" del capitalismo financiero.

Tax Justice Network hace algún tiempo indicó que la fuga de capitales de Argentina asciende a un acumulado de riquezas ocultas en paraísos fiscales que superan los u\$s 399 mil millones. Es la libre movilidad de capitales con su contracara en el endeudamiento externo, fuga de divisas y ocultamiento de dinero en los paraísos fiscales que evidencian los "Panamá Papers". 
Asimismo, Macri le abrió nuevamente las puertas al F.M.I. Es sabido que los programas de estabilización del F.M.I. se basan en una teoría económica: el equilibrio interno y de pagos externos se logra reduciendo el consumo, adaptándose a las pautas internacionales de comercio y producción, y reduciendo el gasto público. Ello trae como consecuencia una baja en el nivel de vida de los grupos de menores ingresos por la disminución de sus consumos y sus demandas; paralelamente, promueve un aumento de las ganancias de bancos, grupos financieros, y una succión de riquezas naturales. "La politica de ingresos que resulta de los programas del F.M.I. en esencia, tiene como objetivo la extracción de recursos del pais deudor para transferirlos al pais acreedor desarrollado, sin el menor examen de las causas de la presunta deuda ni de las consecuencias de su pago" (Calcagno, 1987).

Sin duda las políticas de Macri benefician a pocos y perjudican a muchos. Lo cual fue impulsado por iniciativas que insistentemente se reclamaban desde los centros de la ortodoxia neoliberal: eliminación de impuestos a sectores de altos ingresos -retenciones al campo y la minería-, mega devaluación, incremento a los beneficios por la actividad bancaria, tarifazo e indiscriminada apertura de importaciones.

Estas medidas no podrían tener otro resultado que caída de la economía con elevada inflación, recesión y cierre de empresas. Es el contraste de la proclamada "pobreza cero" con la dura realidad de la economía.

Las politicas del gobierno de Macri generaron las condiciones para el regreso del F.M.I. y el incremento del endeudamiento. Ello, vuelve a ser una cuestión gravísima y condicionará todas las políticas económicas. El carácter ilegal, ilegítimo e impagable del endeudamiento, deberá ser encarado e impugnado firmemente, en todos los ámbitos e instancias que sea necesario. Es la trama jurídica de sometimiento, y un instrumento 
para el saqueo de nuestros recursos naturales que refleja la esencia de una situación colonial.

\section{La Constitución y las politicas}

Es necesario hurgar en la historia económica y constitucional para encontrar el inicio de la etapa que conduce a la actual telaraña de sometimiento, cómo se fue gestando, quienes la impulsaron, como también las políticas y diseños técnico-jurídico utilizados para su concepción y ejecución. Y por cierto, de qué modo se restauran en la actualidad.

Pero, previamente entendemos necesario tratar un aspecto esencial del tema, y precisar que en su integridad la Constitución es, ciertamente, una estructura multidimensional: cultural-económica en la base Constitucional real- y jurídico-institucional en el vértice -Constitución jurídico-formal-. La Constitución real es la suma de los factores de poder -tanto internos como externos- que predominan en una sociedad determinada. Desde el momento en que se recuperó la noción de la realidad conceptual de la Constitución, frente a la ideología que presentaba a la Constitución escrita abarcando la realidad global de la Constitución, quedaron claramente conceptuadas la infraestructura sociológica y la sobre estructura jurídica de la Constitución. Y como a estos dos aspectos de una misma realidad se los llamó Constitución, hubo que diferenciarlos con nombres complementarios: al primero se lo llamó Constitución real y al segundo Constitución escrita o jurídicoformal.

El tema constitucional no pasa solo por la Constitución escrita, que está sujeta férreamente por la Constitución real, ni es exclusivamente un tema jurídico, sino que principalmente se encuentra en el ámbito del 
poder político y de un proyecto de nación compartido por un pueblo organizado y participe directo de su institucionalización al más alto rango normativo. Una Constitución no es sino su consecuencia, y el poder encarna la única instancia capaz de transformar la política en historia. Es ineludible tener presente la correlación que existe entre la Constitución real y la Constitución escrita; y también la afirmación de la justicia que debe contener la Constitución real atento a las condiciones sociales de producción y cultura. La adecuación a tales condiciones sociales conforma los criterios para valorar la Constitución real y a la Constitución escrita; y así, esos criterios vienen a servir de ideales para animar la lucha del pueblo por una Constitución mejor.

Fue a partir del golpe de Estado de 1955 con la "Proclama" del 27 de abril de 1956 que derogó la Constitución Nacional de 1949, cuando dan comienzo políticas económicas que postulan al capital extranjero como motor del desarrollo, otorgan prioridad al mercado y marginan al Estado del proceso económico. Con las políticas enunciadas en dicha "Proclama" se abandonan los principios sociales de la Constitución de 1949 y las normas de política económica que la misma contenía en el Capítulo IV, de su Primera Parte.

La proclamada defensa de la democracia que se invocó en ese período de facto encubrió un retorno al liberalismo económico. En ese tiempo la Argentina no tenía deuda externa que condicionara sus politicas económicas y sociales, ni estaba sometida al F.M.I. A partir de esa ruptura del orden constitucional vigente se produce un retroceso restaurador de minoritarios sectores, que adquieren predominio en la Constitución realy proscriben al proyecto económico, social, político y cultural institucionalizado en la Constitución Nacional de 1949.

El quiebre constitucional iba acompañado por una nueva orientación de la politica social y un retorno a la ortodoxia económica. Las profundas 
transformaciones que se producen en el ámbito de la Constitución real a partir de la derogación de la Constitución Nacional de 1949 y la restauración de la Constitución de 1853/60, con su modelo agroexportador liberal y el capital externo como motor de la economía, abrieron las puertas al endeudamiento externo con instrumentos jurídicos de ocasión que utilizaron para imponerlo.

\section{E1 tiempo del FMI y sus condicionamientos}

Por Decreto-ley N 7.103, del 19 de abril de 1956 -uno de los firmantes y propulsores era Krieger Vasena, entonces ministro de Hacienda de Aramburu-, el gobierno de factoinicia los trámites para obtener el ingreso de la República Argentina a los organismos financieros internacionales que surgieron a partir de los acuerdos de Bretton Woods. Mediante el Decreto-ley No 15.970 del 31 de agosto de 1956 -"Boletín Oficial”, 12. IX.56- se dispuso formalmente la adhesión a esas instituciones financieras, asignando carácter de ley nacional al Convenio Constitutivo del F.M.I. Según se reconoció "la Argentina es el único país de América Latina que no participa de estas instituciones" -v. Capítulo IX, 4, del "Plan Prebisch"-.

Por el Decreto 20.552, el 13.11.56, se constituye el Comité Argentino para negociaciones financieras con el exterior; y el Decreto-ley 373 del 16.1.57 aprueba el valor par de la moneda argentina concertado con el F.M.I. Fueron entonces dichas autoridades de facto siguiendo las recomendaciones imperativas del Plan Prebisch, quienes ingresaron a la Argentina en el F.M.I y al Banco Mundial. De tal modo, se adhirió a los Acuerdos de Bretton Woods, que Perón consideraba un engaño (Rouquié, 1981) (Cholvis, 2013). 
Las políticas económicas que promovió el F.M.I fueron implementadas en el marco establecido por los estatutos del organismo -en el artículo V, Sección $3^{\mathrm{a}}$ y artículo XXXb- a través del denominado acuerdo de crédito contingente conocido comúnmente como "stand-by". Se subordina la conclusión del acuerdo "stand-by" a la realización por parte del gobierno solicitante de un plan económico de estabilización y de ajuste interno inserto en una "Carta de Intención" y en un "Memorando de Entendimiento", entre el país que solicita el crédito y el F.M.I. Durante el curso de la primera década que prosiguió a los Acuerdos de Bretton Woods fue cuando el Fondo sentó las bases del esquema de condicionalidad y a partir de ese momento se operó un cambio total en nuestra política económica, la Nación quedaba rendida ante los intereses financieros orquestados desde esos organismos. Ello lo denunció entonces Arturo Enrique Sampay (González Arzac, 1994).

Comenzó así la etapa de la historia nacional durante la cual se aplicaron por distintos hombres y equipos políticas económicas similares, con particular intensidad durante gobiernos de factoy otros surgidos de procesos electorales con proscripciones y democracias restringidas que aplicaron politicas impuestas por los organismos financieros internacionales, con la fundamentación teórica de los mentores del "liberalismo" de turno, aunque con diversos programas y variantes. Ello se aprecia con un somero recorrido de dichas normas publicadas en el Boletín Oficial, que aportan nombres de conocidos personajes que en esa época y años posteriores tuvieron notoria actuación tanto durante los golpes de Estado, como en breves períodos de retorno al orden constitucional.

Con las mencionadas normas de 1957 que iniciaban las políticas del gobierno de facto, se formalizan con el Fondo y organismos oficiales y privados de los Estados Unidos, acuerdos de créditos destinados a apoyar 
el Plan de Estabilización que se había adoptado, y a través de los decretos-leyes 1.327 -7.2.57-, $\mathrm{N}^{\circ} 5.748$-30.5.57-, $\mathrm{N}^{\mathrm{o}} 10.490$-4.9.57-y $\mathrm{N}^{\mathrm{o}} 10.871$-11.9.57- se ratificaron diversos acuerdos con el Export-Import Bank de Washington.

En enero de 1958 se firmó un acuerdo "stand-by", y se aplican las medidas monetaristas elaboradas por el Fondo, impuestas a los más diversos países con poca consideración por sus particularidades autóctonas. Sin embargo, el presidente Arturo H. Illia encaró los problemas de pagos externos sin firmar un acuerdo stand by con el Fondo. Sólo pidió una autorización de giro para un segundo tramo del crédito condicionado a la aprobación de un programa económico que tenía otorgado el país y era el paso inmediato a un stand by, pero que se negó a solicitarlo para evitar condicionamientos. Renegoció la deuda con el Club de París que mantenía la Nación sin la intervención del Fondo.

Los sectores domésticos ortodoxos, vinculados con las finanzas internacionales, estruendosamente levantaron sus voces críticas, y ello habrá sido uno de los principales motivos que los llevaron a impulsar y dar el golpe de Estado del 28 de junio de 1966. El 13 de marzo de 1967 durante el gobierno de facto de Onganía, se firmó un "acuerdo stand by", que implementó las medidas de política económica que fueron el preludio hacia el "Cordobazo". A pesar de lo cual las otras etapas de la denominada "Revolución Argentina", no se alejaron de las políticas que imponian los organismos financieros internacionales.

De tal modo, la Nación se movía al ritmo que le fijaban las "Cartas de Intención" y los "Memorandos de Entendimiento" dando cumplimiento a los programas económicos de “ajuste”. Esta relación que la Argentina institucionalizaba con los organismos financieros internacionales fue lo que "les permitió daral país sus contundentes recomendaciones" (Romero, 2001). 
La Argentina por esas vías sufrió una limitación sustancial en el ejercicio de su soberanía con la transferencia de la decisión nacional en la confección y ejecución de los programas económicos, e "ingresa asien la última escala de los países subdesarrollados, en los que la asistencia técnica de los organismos internacionales termina configurando una verdadera intervención extranjera" (Jauretche, 1969).

La Argentina estuvo impedida de tomar decisiones soberanas sobre la moneda y políticas económicas, y perdió dicho aspecto esencial de la soberanía. No puede dudarse que los países deben definir en forma autónoma y soberana sus políticas económicas, en especial en los temas monetarios, financieros y crediticios.

Luego del interregno de la Presidencia de Héctor Campora, con abrumadora mayoría de votos Juan D. Perón asume la presidencia de la República e impulsa politicas para fortalecer al Estado en su función de promover el desarrollo económico y encuadrar a los distintos sectores de la economía al cumplimiento de tan alto objetivo, y en diciembre de 1973 consagra el "Plan Trienal para la Reconstrucción y la Liberación Nacional". En ese contexto, y el firme marco de dichas políticas, el F.M.I. no pudo promover ni aplicar sus recetas económicas.

Al poco tiempo se produce el deceso de Perón, y el $1^{\circ}$ de julio de 1974 asume la presidencia María E. de Perón. Poco después ocurre la hecatombe que provocaron las concepciones liberal-ortodoxas impulsadas por el plan de Celestino Rodrigo, y se hicieron notorios los cambios que se venían produciendo en el ámbito de la Constitución real.

\section{En 1976 se acentúa la presencia del F.M.I.}

Después de derrocado el gobierno constitucional por el golpe de Estado del 24 de marzo de 1976 y en el marco de la supraconstitucionalidad de 
facto dichas políticas continuaron y se acentuaron con diseños basados en desarrollos teóricos de corte liberal o "neoliberal", que se expandieron desde los centros del poder económico mundial durante finales de las décadas del setenta y del ochenta. De tal modo, nuestro país se encontró periódicamente recorrido por funcionarios del F.M.I., que desarrollaban la primera etapa de una tarea de relevamiento de datos, para obtener pormenores de lo sucedido en nuestra política fiscal, monetaria y cambiaria, y otras variables de la economía. La segunda etapa transcurria en Washington donde se contabilizan los datos y se verificaba si la Argentina había cumplido o no con las pautas acordadas para los períodos en consideración, en el marco del "stand-by" vigente.

Pero también llegaron los economistas de los bancos acreedores que integraron un "steering commitee" de la Argentina o Club de acreedores, para realizar un monitoreo de las cuentas del país, por si esos relevamientos y verificaciones precedentes no fueron suficientes en su concepto, para que se suscribiera el "acuerdo" con los bancos acreedores del exterior sobre refinanciación de la deuda.

Posteriormente, ante las reacciones de los sectores afectados por dichas conformidades si el Gobierno de turno no podía dar un estricto cumplimiento a lo comprometido, venía un "waiver" -dispensa o perdóno nueva oportunidad, y otras declaraciones para dejar justificados los desvíos acordados. Como última alternativa venía un préstamo puente, lo cual era la postrer "red de seguridad" a cerrar con el Tesoro de los EE.UU, para superar cualquier dificultad en la refinanciación acorde a los intereses de los bancos acreedores.

En ese marco, forzaron la adopción de un conjunto de politicas orientadas a reducir a un mínimo los ámbitos de ejercicio de la soberanía y acotar el margen de mediación estatal. Fue un punto de inflexión 
decisivo en la decadencia de la idea del Estado, y la democracia recuperada en 1983 heredó un Estado desmantelado.

Así fue que aún luego de restablecida la vigencia de la Constitución histórica, durante la presidencia de Raúl Alfonsín, entre diciembre de 1984 y septiembre de 1988 también se suscribieron con el F.M.I. numerosos acuerdos "stand by", "Memorándums de Entendimiento", y "Carta de Intención"; pero también una "Carta Política de Desarrollo", suscripta con el Banco Mundial, anunciada en Berlín el 26.6.98.

En base a dichos instrumentos el F.M.I. -y también el Banco Mundialasumieron una función de co-redacción y vigilancia del cumplimiento de los programas económicos de "ajuste". El "modelo" adquiere su expresión final y más acabada a partir de las políticas económicas que se inician en el período presidencial de Carlos Menem que comienza en 1989.

La situación que postraba y padecía nuestro país no pudo ser resuelta con la reforma constitucional de 1994, pues las características del proceso político que llevó a su sanción impidieron que el pueblo tuviera participación, y se perdió la oportunidad de recurrir al único medio que habria permitido hacer tambalear a la Constitución real que condicionaba la reforma. Es que el texto constitucional de 1994 nace sin participación popular, y desde su inicio fue impulsado por un acuerdo de "cúpulas" en donde el pueblo estuvo ausente. Lo cual no fue el marco adecuado para legitimar e impulsar una nueva etapa en la vida constitucional de la Nación. Significó un camino casi similar al que se transitó para sancionar o reformar las constituciones en el siglo XIX.

Dicho proceder impidió que surja un texto avanzado que coadyuve al progreso social, tal como propusieron algunos convencionales constituyentes. 
Así fue que después de sancionada la reforma al texto constitucional en 1994 y hasta el 2001, se firmaron seis acuerdos con el Fondo, y tres ampliaciones que acompañaron el programa económico durante la presidencia de Carlos Menem.

El modelo encuadraba en términos generales en las recomendaciones del "Consenso de Washington", funcional a los intereses estratégicos y comerciales de los EE.UU; y el F.M.I. fue un instrumento para forzar la adopción de esas políticas. Argentina marchó al ritmo que le marcaron las instituciones internacionales de crédito, tal el F.M.I. y el Banco Mundial, como también la banca acreedora extranjera y organismos gubernamentales y no gubernamentales de los países altamente desarrollados; y por grupos económicos transnacionales y otros de origen nacional. El gobierno se comprometía a obtener resultados en materia de empleo, reducción del gasto público, flexibilidad y renegociación de convenciones de trabajo; reforma de obras sociales y también incluía compromisos sobre exportaciones, déficit fiscal, reforma tributaria, fusión o eliminación de organismos del Estado.

Entonces durante las últimas décadas del siglo $\mathrm{XX}$ y aún con la reforma de 1994, a consecuencia de la política iniciada con los instrumentos que se sancionaron por el golpe de Estado de 1955, continuada por la supraconstitucionalidad de facto que instrumentaron sus "Actas", "Fines" y "Estatutos" (Cholvis, 2016), y la innegable frustración de los sectores populares para hacer efectivo un proyecto de Nación que nos inserte en la realidad socioeconómica del mundo contemporáneo en condiciones adecuadas para generar un desarrollo político y económico acordes a nuestras posibilidades como Nación, se consolidó la presencia que habían logrado los organismos financieros internacionales y poderosos grupos económicos extranjeros y nacionales ligados a ellos, que se transformaran en soportes determinantes de la 
Constitución real del país lo cual les abrió el camino para que tomaran abierta posesión de nuestra economía.

El 21 de diciembre de 2000, durante la presidencia de Fernando de la Rúa se anunció la nueva Carta de Intención del Gobierno argentino al F.M.I., y el Memorando de Política Económica, respaldado por el acuerdo de crédito contingente aprobado por el F.M.I.

En los doce años transcurridos entre 1989 y 2001, Argentina permaneció continuamente bajo programas del F.M.I., a través de cuatro acuerdos stand by -en 1989, 1991, 1996 y 2000, ampliado en enero y agosto de 2001-; y dos convenios de facilidades extendidas -en 1992, aumentado en 1995 y en 1998-.

\section{E1 siglo XXI llega con una gran crisis social}

Es sabido el notorio fracaso de dichas políticas y los graves perjuicios que ocasionó al pueblo argentino. El deterioro de las finanzas públicas, agobiadas por la carga de la deuda y la caída de la recaudación a causa de la continua recesión, precipitó una serie de medidas desesperadas para sostener la convertibilidad y evitar la devaluación, pero no impidieron la explosiva crisis estructural de fines de 2001 y principios del 2002.

Las reacciones populares, a consecuencia de las políticas seguidas son conocidas y sus causas notorias. La crisis socio-económica, la declaración del estado de sitio, y las reacciones populares del 19 y 20 de diciembre de 2001, finalmente impulsaron la renuncia de De la Rúa. Cuando todavía retumbaban en la Plaza de Mayo los ecos siniestros de la represión desatada, se producen rápidos cambios en la conducción ejecutiva de la Nación, y el 24 de diciembre de 2001 luego de asumir la presidencia de la República, Adolfo Rodríguez Saa con una emotiva 
declaración en el Congreso Nacional anuncia el diferimiento de los pagos de los servicios de amortización de capital e intereses de la deuda pública externa, y que se iniciarian negociaciones con los acreedores externos para reestructurar las obligaciones contraídas. Pocos días después, el 29 de diciembre Adolfo Rodríguez Saa debe renunciar al cargo. Es en esos azarosos días que se va definiendo la situación política en el marco institucional vigente, y asume el Poder Ejecutivo Nacional Eduardo Duhalde.

Dado que la Ley $\mathrm{N}^{\circ} 25.561$ había declarado la emergencia pública en materia social, económica, administrativa, financiera y cambiaria, y delegó facultades al P.E.N. hasta el 10 de diciembre de 2003, y que la Decisión Administrativa $\mathrm{N}^{\circ} 1 / 2002$ respecto a obligaciones de la deuda pública se hallaban condicionadas por la escasez de recursos con que cuenta el Tesoro Nacional, se inició el proceso de reprogramación de las obligaciones y pago de la deuda.

El artículo $1^{\circ}$ del Decreto 256 facultó al Ministerio de Economía a esos efectos -"Boletín Oficial”, 8/2/2002-, y el gobierno argentino firmó el 16 de enero de 2003 una Carta de Intención con el F.M.I., para un acuerdo de reprogramación de vencimientos de deuda hasta el 31 de agosto de 2003. La Carta de Intención incluía un Memorando de Políticas Económicas para un programa de transición en el 2003 y un Memorando de Entendimiento Técnico.

De la lectura del acuerdo se aprecia que se lo entendía como "programa de transición”, entre la crisis de fines de 2001 y el momento de la firma; o sea, desde el ingreso de Roberto Lavagna como Ministro en mayo de 2002 en la gestión de Eduardo Duhalde, y pocos meses después de la asunción de Néstor Kirchner a la presidencia. 


\section{Inicio de una distinta relación con el F.M.I.}

El Director Gerente del F.M.I., Rodrigo Rato promovía prorrogar el stand by que vencía en septiembre de 2003 por otro año más, pero imponiendo condiciones más rígidas a la Argentina que no fueron aceptadas ni por el presidente Néstor Kirchner ni por su ministro Roberto Lavagna y el equipo económico encabezado por el viceministro Guillermo Nielsen. Finalmente, el 17 de septiembre de 2004 Kirchner y Lavagna deciden no firmar un nuevo acuerdo con el F.M.I. y se suspende la relación a partir de ese momento.

Posteriormenteel presidente Kirchner amplió su anhelo de liberarse de la tutela del F.M.I. al anunciar durante un acto en la Casa Rosada el 15 de septiembre de 2005 la cancelación total de la deuda de la Argentina con ese organismo. Afirmó en ese acto que la cancelación de la deuda con el F.M.I. servirá para ganar grados de libertad para la decisión nacional y le permitirá al país no estar obligado a atender las exigencias del organismo a la hora de negociar los acuerdos de refinanciación de los vencimientos de la deuda externa (La Nación, 2005).

El país se ponía en la senda de la soberanía política e independencia económica. "La Argentina a bonará anticipadamente al F.M.I. la suma total adeudada de 9.810 millones de dólares", dijo el presidente con énfasis y contenido júbilo, en un acto al que asistieron todos los ministros, los gobernadores y legisladores, con particular apoyo de los radicales. Roberto Lavagna respaldó con énfasis la noticia: "La Argentina hizo punta en la politica de desendeudamiento desde 2002. Ese es desde mi punto de vista el camino correcto" (La Nación, 2005).

El 22 de diciembre de 2005, la Cámara de Diputados aprobó el decreto de necesidad y urgencia que había dictado el gobierno para pagar/cancelar el pasivo argentino con el F.M.I. Poco después fue 
aprobado en el Senado. El 5 de enero de 2006 se efectivizó el pago anticipado del total de la deuda pública con el F.M.I.

Así fue que el vínculo entre el F.M.I. y la Argentina a partir del gobierno de Néstor Kirchner inicia un período de distanciamiento que se extendió por más de diez años. Tal motivo ocasionó que en mayo de 2012, el F.M.I. abandone su sede en Argentina y destina sólo un economista a tiempo completo, establecido en Perú.

Los años finales de la gestión presidencial de Cristina Fernández de Kirchner ofrecen el espectáculo poco frecuente en la política argentina de los últimos años de un gobierno intentando preservar el núcleo de su proyecto originario por encima de las dificultades sobrevinientes. Ante la necesidad de flexibilizar el frente externo regularizó la relación con el CIADI, y con el Club de París, promovió la diversificación de relaciones económicas y comerciales con nuevas contrapartes -la República Popular China, Medio Oriente- e instaló en la agenda de la ONU y en la opinión internacional la posición argentina en el litigio con los fondos buitre (Vilas, 2017).

Durante la disputa Argentina y los buitres, el F.M.I. mantuvo una postura errática y distante. En 2014 advirtió que las decisiones de la justicia estadounidense podian afectar futuras reestructuraciones y se limitó a respaldar la propuesta del "mercado" para reforzar las cláusulas contractuales de los bonos de la deuda soberana. Desestimó así acompañar la creación de un mecanismo internacional que guie las reestructuraciones de deuda. Por ello, se debe tener presente que como final del largo proceso de reestructuración de deuda, impulsado por Néstor Kirchner y Cristina Fernández de Kirchner, por iniciativa de la República Argentina el 10 de septiembre de 2015 la Asamblea General de la ONU en su $69^{\circ}$ período de sesiones aprueba los "Principios Básicos de los Procesos de Reestructuración de la Deuda Externa” (Resolución $\mathrm{N}^{\circ}$ 
A/RES/69/319), y nuestro país el 4 de noviembre de 2015 por la Ley 27.207 los declaró de orden público e integrantes del ordenamiento jurídico argentino -arts. $1^{\circ}$ y $2^{\circ}-($ Cholvis, 2018).

\section{La etapa actual de sometimiento neocolonial}

Ahora estamos en otra etapa con una concepción que retrotrae a duros tiempos vividos. El gobierno y el F.M.I. coinciden en las prioridades que debe asumir la política económica. Luego del pago a los Fondos Buitre, el F.M.I. arribó nuevamente e instala una misión de técnicos con la tarea de revisar las cuentas del país.

Dirigidos por Roberto Cardarelli visitaron la Argentina entre el 19 y el 29 de septiembre de 2016 y llevaron a cabo la primera consulta del Artículo IV, que desde el año 2006 no se realizaba. El pago a los fondos buitre, la reinserción en los mercados internacionales de deuda externa y la desregulación del mercado cambiario fueron celebrados por el F.M.I. Normalizada dicha relación bilateral se profundizan los "cambios" en esa dirección y la política económica promovida por el F.M.I. e implementada por el gobierno nacional, agrava la problemática de la Argentina.

Actualmente economistas del F.M.I. vuelven a monitorear las cuentas nacionales y se hace notoria su influencia. Los documentos oficiales del organismo para la Argentina recomiendan profundizar el ajuste, recortar el gasto público, reformar el sistema jubilatorio y la flexibilizació n laboral. En actitud servicial el gobierno se somete a esa coyunda y aplica las políticas que le imponen. El Director Ejecutivo del Hemisferio Occidental del F.M.I., Alejandro Werner al poco tiempo salió a respaldar al gobierno nacional e hizo propio el relato macrista de la "pesada herencia" (Werner, 2019). 
Principales funcionarios del gobierno nacional recorren los salones del F.M.I., son acogidos allí con agrado al verlos postrarse y formular anuncios de que ejecutarán políticas nacidas del organismo, incitados por el recóndito anhelo de disfrutar las interesadas loas y caricias que allí se les brindan.

Así fue que la Argentina en abril de 2018 firmó un préstamo "standby", y Macri suscribe un acuerdo con el F.M.I. que vence en el año 2021, abarcando el fin de su mandato y los dos primeros años de la nueva administración que será electa en el 2019.

Las "recomendaciones" ofrecidas por el F.M.I., para el préstamo "stand by" de u\$s 57.100 millones son conocidas: reducción del déficit, mayor apertura comercial, liberalización financiera y profundización de lo que denomina "reformas estructurales", que impone para aplicar sus condicionamientos, como ser leyes para reformar la Carta Orgánica del Banco Central, de reforma laboral y previsional y que el FGS pueda ir siendo liquidado.

El acuerdo con el F.M.I. lleva al estancamiento permanente por el ajuste fiscal y monetario que exige, y deja la economía sujeta a un círculo vicioso de deterioro.

Después de celebrar los acuerdos con el F.M.I., el gobierno presentó el proyecto de Ley de Presupuesto 2019. Ciertamente, el encuadre de los acuerdos y el presupuesto se nutren de la conocida tesis de dicho organismo de impulsar un creciente superávit fiscal para cubrir el pretendido endeudamiento exterior. Mantiene la exigencia del ajuste, a pesar de haber asfixiado al país con esa misma política, y como ocurrió en anteriores etapas que llevaron al sometimiento del F.M.I., sostiene duras e impopulares medidas que recaerán sobre las espaldas del pueblo argentino. 
La conducción económica rendía examen en Washington el viernes 12 de abril de 2019. La postura del F.M.I. en esencia no ha variado, es la antigua receta. No servirá para solucionar el endeudamiento ni para impulsar un desarrollo económico soberano. Afectando la política interna de un país soberano, Lagarde titular del F.M.I. ahora da consejos a los candidatos del próximo proceso electoral: "Sería una tontera para cualquier candidato dar la espalda al trabajo en curso".

Argentina se encuentra inmersa en el ecosistema de la globalización financiera que resta poder a los Estados y erosiona las democracias. Bien se expresó que no existe chance de recuperación sostenida si la economía está bajo vigilancia ortodoxa del F.M.I. La experiencia Argentina y de otros países que se sometieron a su receta así lo indica.

Hay que sacarse de encima al F.M.I., como se hizo en 2005. Sin liberarse del F.M.I. no hay posibilidades de reconstruir el país de las ruinas que dejará el fracaso de este ciclo neoliberal. Las políticas del F.M.I. conducen a una economía inviable en términos de bienestar social. Es imprescindible sacarse la tutoría del F.M.I. (Zaiat, 2019).

\section{Volver a la senda de una nación soberana}

Sin un cambio profundo de política económica el año 2020 será inviable. Las únicas fórmulas no son el neoliberalismo y las recetas del F.M.I. Debemos configurar una Nación con capacidad suficiente de decisión nacional, y no una Nación en apariencia que conserva los atributos formales del poder pero no su esencia. Está claro que la República Argentina no debió renunciar a su soberanía, dejando que las cartas de intención, los memorados de entendimientos y los acuerdos de derechos de giro "stand-by", suscriptos por funcionarios para 
comprometernos con el F.M.I. y otros organismos internacionales de crédito, se interpusieran en las decisiones del gobierno nacional.

Un país que aspira a desarrollarse integralmente no puede dejar en manos ajenas el manejo de ciertos engranajes de su mecanismo productivo, si es que no quiere que su economía sea un acoplado de la economía extraña que le manipula esas piezas esenciales.

Debió haber quedado como triste recuerdo los tiempos en que las "Cartas de Intención", los "Memorandos de Entendimiento" y los "Acuerdos de Derecho de Giro" “stand-by", suscriptos por funcionarios para comprometernos con el F.M.I. y otros organismos internacionales de crédito, se transformaban en un soporte de máximo rango en la conformación de la Constitución real del país, que sometió y condicionó a la Constitución jurídica (Cholvis, 2013 -b).

En base a dichos instrumentos el F.M.I. asumió una función de coredacción y vigilancia del cumplimiento de los programas económicos de “ajuste". El país por esas vías sufrió un desmedro sustancial en el ejercicio de su soberanía. La dependencia se concretó en la transferencia de la decisión nacional en la confección de los programas económicos. Por ello, como resultado de profundizar el debate contemporáneo y la participación protagónica de los distintos sectores sociales, una nueva Constitución deberá encarar y enmarcar debidamente este problema, para consolidar la soberanía nacional y efectivizar los derechos del pueblo. 


\section{Referencias}

Calcagno, Alfredo E. (1987). "Algunos aspectos de la deuda externa en América Latina con particular referencia a Argentina", en "Políticas de ajuste y grupos más vulnerables en América Latina-Hacia un enfoque alternativo", Eduardo S. Bustelo, Fondo de Cultura Económica, Bogotá.

Cholvis, Jorge F. (2013). "Perón y el F.M.I.", en "La Constitución y otros temas (Dilemas del constitucionalismo arge ntino)", tomo III, "Diversas cuestiones constitucionales", El Cid Editor, Buenos Aires.

Cholvis, Jorge F. (2013 b). “¿Por qué la Constitución”, INFOJUS, Año II-N 4, Buenos Aires.

Cholvis, Jorge F. (2016). "Revisionismo Histórico Constitucional. Proyecto Nacional y Constitución”, Ediciones Fabro, Buenos Aires.

Cholvis, Jorge F. (2018). “Constitución, endeudamiento y políticas soberanas”, Vuelta a Casa Editorial, La Plata.

González Arzac, Alberto (1994). "Convenciones Constituyentes”, en "Nueva Constitución de la Re pública Argentina”, Editorial Negri, Buenos Aires.

Jaure tche, Arturo (1969). "El retorno al coloniaje. La segunda década infame: de Prebish a KriegerVasena”, Ediciones del Mar Dulce, Buenos Aires.

La Nación (16 de diciembre de 2005). "Histórico: el país saldará en un solo pago la deuda con el FMI" Recuperado de https:/ / www.lanacion.com.ar/politica/historico-el-paissaldara-en-un-solo-pago-la-deuda-con-el-fmi-nid765314

Romero, Luis A. (2001). "Breve historia contemporánea de la Argentina”, 2 a edición, Fondo de Cultura Económica, Buenos Aires.

Rouquié, Alain (1981). "Poder militar y sociedad politica en Arge ntina", Emece Editores, Buenos Aires.

Vilas, Carlos M. (2017). "Política, Estado y clases en el Kirchnerismo: una interpretación", Realidad Económica N³05.

Werner A. (2019). "Perspectivas para América Latina y el Caribe: Nuevos retos al crecimiento" Dialogo a Fondo. Blog del F.M.I. sobre América Latina. Recuperado de https: / / blog-dialogoafondo.imf.org/?p=12795

Zaiat, Alfredo (2019). “Sacarse de encimaal F.M.I.”, Página/12, 14 de abril de 2019. 